\title{
PET artefact masquerading as a PET positive lung
}

\section{mass}

\author{
Pichapong Tunsupon, M Jeffery Mador
}

University at Buffalo, State University of New York at Buffalo, Veteran Hospital, Buffalo, New York, USA

\section{Correspondence to} Dr Pichapong Tunsupon, ptunsupon@gmail.com

Accepted 26 November 2015

\section{DESCRIPTION}

A 70-year-old man was referred for evaluation of multiple lung nodules. His medical history was significant for stage IV non-Hodgkin's lymphoma in remission for the past 10 years. Physical examination and laboratory tests were unremarkable. Positron emission tomography and CT (PET-CT) of the chest demonstrated non-hypermetabolic scattered pulmonary nodules measuring up to $1.0 \mathrm{~cm}$ in diameter and an intense fluorodeoxyglucose (FDG)-avid hypermetabolic lesion adjacent to the right hilum extending to the medial segment of the right lower lung (RLL), without any corresponding

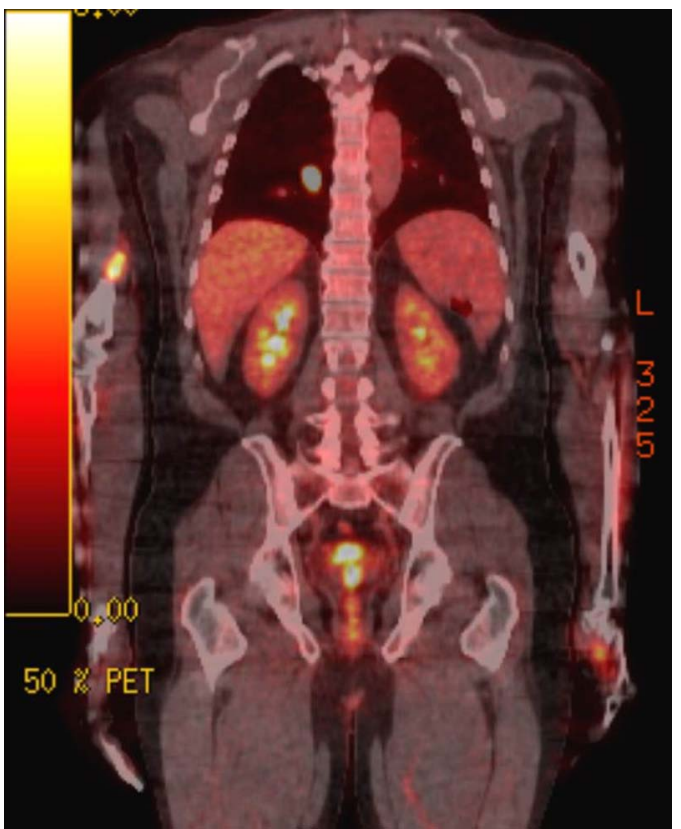

Figure 1 Coronal plane of the positron emission tomography-CT scan demonstrates fluorodeoxyglucoseavid hypermetabolic lesion adjacent to the right hilum.

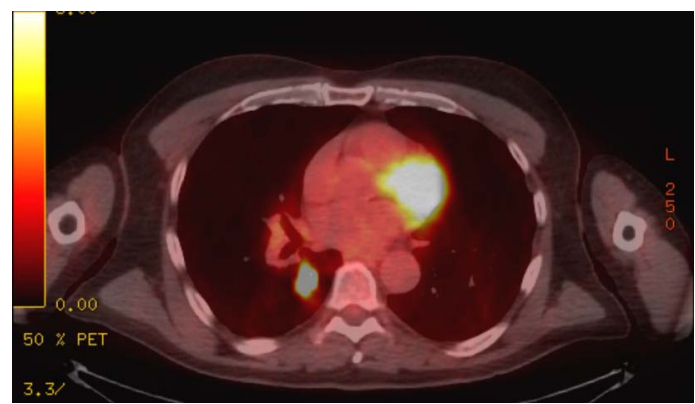

Figure 2 Transaxial plane of the positron emission tomography-CT scan demonstrates fluorodeoxyglucoseavid hypermetabolic lesion adjacent to the right hilum. abnormality on the chest CT (figures 1-3). This lesion had standardised uptake values of 55 on the transaxial plane. Bronchoscopic examination of the RLL showed patent airways without any endobronchial lesion. Cultures, smear and cytology from bronchoalveolar lavage of the RLL were nondiagnostic. The abnormal FDG-avid hypermetabolic lesion in the RLL disappeared on follow-up PET-CT (figure 4).

We illustrate an unusual artefact that is explained by the formation of an FDG-containing blood clot during or after injection, ${ }^{1}$ which leads to microembolism in the pulmonary capillaries extending to the peripheral portion of the lung. Sometimes, this is more frequent if the injector withdraws blood to confirm intravenous patency resulting in blood combining with FDG in the syringe, which is then re-injected. This phenomenon does not result in any clinical symptoms and its true incidence is not known. ${ }^{2}$ A late time point image can be useful as the abnormality can disappear after an hour, confirming the artefact.

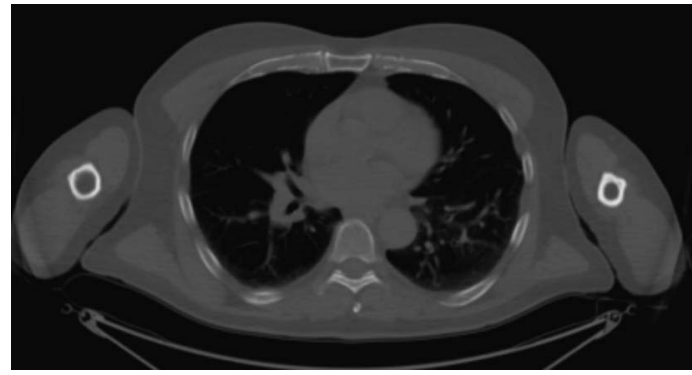

Figure 3 Transaxial plane of the co-registered CT of the chest does not show any corresponding abnormality in the area of the positron emission tomography-positive lesion.

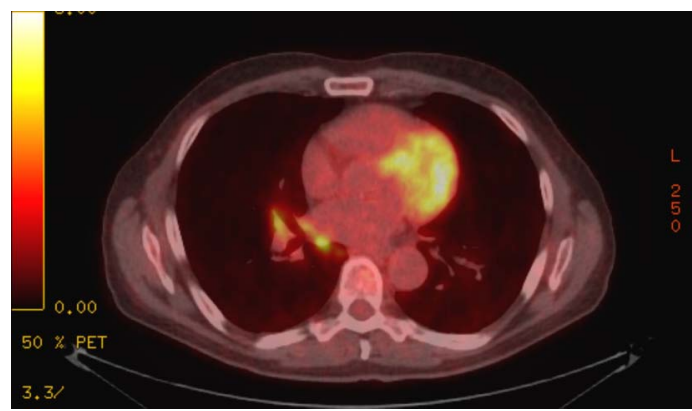

Figure 4 The fluorodeoxyglucose-avid hypermetabolic lesion adjacent to the right hilum has disappeared without any intervention on repeat positron emission tomography-CT. 


\section{Learning points}

- When interpreting intrapulmonary fluorodeoxyglucose-avid hypermetabolic lesions, anatomical correlation with co-registered CT image must be performed to avoid misdiagnosis or overstaging of malignancy.

- When no abnormality is seen on the chest CT in the area of the positron emission tomography-positive lesion, artefacts such as blood clot injection artefact should be suspected.
Contributors PT and MJM prepared the manuscript or revised it critically for important intellectual content, and approved the final version before submission to the journal.

Competing interests None declared.

Patient consent Obtained.

Provenance and peer review Not commissioned; externally peer reviewed.

\section{REFERENCES}

1 Sureshbabu W, Mawlawi O. PET/CT imaging artifacts. J Nucl Med Technol 2005;33:156-61; quiz 63-4.

2 Hany TF, Heuberger J, von Schulthess GK. latrogenic FDG foci in the lungs: a pitfall of PET image interpretation. Eur Radiol 2003;13:2122-7.

Copyright 2015 BMJ Publishing Group. All rights reserved. For permission to reuse any of this content visit http://group.bmi.com/group/rights-licensing/permissions.

BMJ Case Report Fellows may re-use this article for personal use and teaching without any further permission.

Become a Fellow of BMJ Case Reports today and you can:

- Submit as many cases as you like

- Enjoy fast sympathetic peer review and rapid publication of accepted articles

- Access all the published articles

- Re-use any of the published material for personal use and teaching without further permission

For information on Institutional Fellowships contact consortiasales@bmjgroup.com

Visit casereports.bmj.com for more articles like this and to become a Fellow 